\title{
LEVEL OF MOTHER-BABY BONDING AND INFLUENCING FACTORS DURING PREGNANCY AND POSTPARTUM PERIOD
}

\author{
Gulseren Daglar ${ }^{1}$ \& Naim Nur ${ }^{2}$ \\ ${ }^{1}$ Cumhuriyet University Faculty of Health Sciences, Department of Midwifery, Sivas, Turkey \\ ${ }^{2}$ Cumhuriyet University Faculty of Medicine, Department of Public Health, Sivas, Turkey
}

received: 2.1.2018;

revised: 28.3.2018;

accepted: 27.6 .2018

\section{SUMMARY}

Background: Bonding is the process of an emotional relationship between mothers and babies. Pregnancy and postpartum periods are most important of developing a mother-child bonding. Here we aimed to determine the level of mother-baby bonding and identify the influencing factors during pregnancy and the postpartum period and to examine the relationship between bonding level during pregnancy and the postpartum period.

Subjects and methods: This cross-sectional descriptive study included twelve districts across a range of socioeconomic structures. Every district was selected by a simple random sampling method. Data were collected with Prenatal Attachment Inventory, Mother-to-Infant Bonding Scale, Center for Epidemiologic Studies' Depression Scale and Beck Anxiety Inventory. The study included two home visits. The first visit at gestational age $\geq 35$ weeks and second visit on the seventh or eighth day of the postpartum period. The study was conducted with 227 pregnant women.

Results: We found that, 50.7\% pregnant women had prenatal depression and $36.6 \%$ pregnant women had postpartum depression. We detected a negative association between depression level during pregnancy and the postpartum period with motherbaby bonding in the postpartum period ( $r=0.174, p=0.009$; and $r=0.221, p=0.001$, respectively). A negative correlation was detected between anxiety level and mother-baby bonding level in the postpartum period $(r=0.151, p=0.023)$. It was found that when the prenatal attachment level increases, the level of postpartum bonding is also increases $(r=0.297, p=0.000)$.

Conclusions: Depression and anxiety levels were higher during pregnancy than the postpartum period. Depression level during pregnancy and postpartum period depression and anxiety level negatively affected mother-baby bonding in the postpartum period. We found that as prenatal attachment level increases, the level of postpartum bonding also increases.

Key words: pregnancy - attachment - maternal baby bonding

$* * * * *$

\section{INTRODUCTION}

The relationship between mother and child formed during the early stage of life is most important because it serves as a prototype for various relationships in later stages of an individual's life. In recent years, there has been an increase in studies on mother-infant bonding (Dubber et al. 2015, Kitamura et al. 2013, Kokubu et al. 2012, Ohoka et al. 2014, Örün et al. 2013, Seimyr et al. 2009, Y1lmaz \& Kizlkaya 2010). Children's later social, emotional, and cognitive development can be affected by the early mother-infant relationship (Ranson \& Urichuk 2008). Thus, it is important to understand the nature of the mother-infant bond during pregnancy and the postpartum period and the factors that affect it.

Physiological, psychological, and social changes occur during pregnancy, and women need preparation to adapt to these new changes. Being unprepared for these conditions during pregnancy and the effects of hormones released during pregnancy can cause emotional discomfort (Cantwell \& Cox 2003). Although serious symptoms of depression/anxiety seldom happen in pregnancy, mild depressive/anxiety symptoms are more common, especially for the first time in pregnancy (Stocky \& Lynch 2000).
Depressive mood during pregnancy and the postpartum period is an important health problem, which negatively affects the mother, infant, and the family (Dennis \& Ross 2006). It has been estimated that depression occurs in approximately $7-15 \%$ of women during pregnancy and $10-15 \%$ of women in the postpartum period (Brockington 2004, O'Keana \& Marsh 2007). In a recent study by O'Keane and Marsh (2007), depression during pregnancy was in the range of 19 to $25 \%$ in developing countries and 7 to $15 \%$ in developed countries.

Women who had prolonged depression symptoms during the postpartum period were significantly more likely to develop cognitive and emotional problems in their mother-infant interaction. Moreover, the negative influences of depression symptoms tend to become more prominent for mother-child bonding when depression during postpartum is extended (Murray et al. 1996a). The recent studies have analyzed the effects of depression symptoms and postpartum depression on early and late stages of child development and found an association between early maternal depression and negative cognitive and emotional infant development (Murray et al. 1996a, O'Keana \& Marsh 2007).

Anxiety is described as a psychological response to long-term stress (Cantwell \& Cox 2003). Concerning 
anxiety, studies have detected a high prevalence of anxiety symptoms in more than $25 \%$ of pregnant women (Britton 2011, Ross \& McLean 2006). Previous research has reported that, in pregnancy, anxiety often occurs, corresponding to depression, and remains the likelihood of postpartum depression (Heron et al. 2004). Figueiredo and Costa (2009) reported that anxiety levels seem to be higher during pregnancy than the postpartum period.

The attachment bond is the process of an emotional relationship between mothers and babies, and it is an important component of the maternal role identity process and in the adaptation to motherhood (Mercer 2004). Mother-baby bonding begins before birth (Cranley 1981). Anxiety or depression during pregnancy and the postpartum period prevents mothers from completely bonding with their baby (Kumar 1997, O’Keana \& Marsh 2007).

Bonding disorders tend to occur when there is difficulty developing an attachment between an infant and its mother. It has been reported that several risk factors, such as unwanted pregnancy, painful delivery, infants with diseases, and death of a twin baby, can cause the onset of bonding disorder (Kumar 1997). Other factors that might affect effective bonding include severe anxiety of a mother, easily-distressed temperaments, infants with difficulty sleeping and feeding, and severe emotional neglect or abuse (Brockington 2004).

There are multiple notions of the mother-infant relationship disorder. One view suggests that the bonding disorder emerges secondary to an untreated primary mother's postpartum depression. Others suggest that the bonding disorder can also occur in women who have not suffered from maternal depression (Brockington 2004).

Mother-infant relationship disorders are estimated to occur in 10-25\% of births. Murray et al. (1996b) assessed the mother-infant relationship, maternal depression, and cognitive function, and found that cognitive functioning was not influenced by the symptoms of maternal depression but was predicted by mother-infant interaction. In a study by Kumar (1997) that investigated women with serious maternal affective disorders, the authors stated that because the sign of mental and bonding disorders very closed, it is difficult to clarify the contexts completely. However, in a recent study by Ohoka et al. (2014), it was reported that mothers who with a low mood are inclined to have a bonding disorder. Also, results suggest that the mood of the mother was closely influenced by the effectiveness of attachment between the mother and child.

There is limited available data about bonding disorders, maternal depression, and anxiety throughout pregnancy and the postpartum period. Research studies are usually carried out on clinical rather than population-based samples. Moreover, many studies have aimed only to report the rates of depression among women during pregnancy, after the childbirth period, or both (Brockington 2004). To address the limited data available on the potential relationship between motherinfant bonding and maternal pre/postpartum mood, here we aimed to investigate the effect of maternal depressive and anxiety symptoms in the pregnancy and early postpartum period on the pattern of infant-mother bonding.

\section{SUBJECTS AND METHODS}

\section{Procedures and Participants}

This cross-sectional population-based study was performed in twelve quarters across different socioeconomic structures and that were chosen by a simple random sampling method in the center of Sivas, a central Anatolian City, Turkey, between 1 March and 1 September 2013. A sampling frame was worked out by making a list of all quarters of Sivas City. In the first stage, 12 quarters (as clusters) were randomly chosen from 62 quarters. After the first initially selected quarter, every subsequent fifth quarter was selected (i.e., $1^{\text {st }}, 6^{\text {th }}$, and $\left.11^{\text {th }}\right)$. Medical records of primary health care centers were used to determine the total pregnant woman population of these quarters at the beginning of the study. Written permission was obtained from the ethical board of ethics committee of Cumhuriyet University, Sivas (Board decision no: 2013-01/14). After obtaining the approval of the Regional Health Directorate and the administrators of the health centers.

This study consisted of two home visits for each participant; the first visit at gestational age $\geq 35$ weeks and second visit on the seventh or eighth day of the postpartum period. The participants were informed orally about the purpose of the study and the length of time it would take. Participants were also informed that their responses would be kept confidential and that they would have the right to withdraw from the study at any time.

Face-to-face interviews, collection of demographic information, and administration of the questionnaires at the respondents' homes were done by the researchers during the study period. The Demographic Information Questionnaire, which was enhanced by the researchers based on the existing literature, consisted of 35 questions and three parts, to collect information on 1) demographic data (maternal age, education, family structure, economic status, etc.); 2) obstetric data (risk status, parity, number of children, sex of the child, etc.); and 3) present pregnancy.

Pregnant women of gestational age of $\geq 35$ weeks, with no communication difficulties, and who gave their informed consent to attend were enrolled into the study. Participants who met the inclusion and exclusion criteria were recruited until the target numbers were reached. A total of 244 pregnant women's homes were visited during the study period; eight did not agree to participate, one had a stillbirth, four were not found at home, four moved away from the study area, and 227 eligible pregnant women were interviewed at their home 
to gather the study data. Verbal and written informed consent was obtained from all subjects after the study was described to them. After a demographic interview, participants were asked to complete the Prenatal Attachment Inventory (PAI) after 35 weeks of pregnancy and to fill out the Mother-to-Infant Bonding Scale (MIBS) at 7/8 days after delivery. Also, participants were required to complete the Center for Epidemiologic Studies' Depression Scale (CES-D) and Beck Anxiety Inventory (BAI) according to the same schedule as the PAI and MIBS. The mentioned instruments were designed to investigate the pattern of maternal-fetal attachment and bonding disorders, as well as the presence of depressive state and anxiety during pregnancy and postpartum period.

\section{Measures}

\section{Prenatal Attachment Inventory (PAI)}

PAI was used to evaluate the mother's feelings, thoughts, and relationship to her fetus during the third trimester of the pregnancy. The PAI was created by Muller in 1993 and consist a of 21 items. The PAI scores can range from one to four. The higher the score, the higher the level of attachment (Muller 1993). The PAI has primarily been adapted into Turkish by Yilmaz, and the Turkish version has a reliability coefficient (Cronbach's alpha) of 0.84. (Y1lmaz 2013)

\section{The Mother-to-Infant Bonding Scale (MIBS)}

The MIBS (Taylor et al. 2005), which was designed to screen the general population for postpartum difficulties, consists of eight items (loving, resentful, neutral or felt nothing, joyful, dislike, protective, disappointed and aggressive), each followed by a four-point Likert scale ranging from zero, "Very much" to 3, "Not at all". When the item reflects a negative emotional response, the scoring is reversed. Thereby possible scores on the MIBS range between zero and 24, with high scores indicating a problematic mother-to-infant bond. The MIBS has previously been adapted into Turkish by Karakulak Aydemir and Alparslan and shows a relatively good reliability with a Cronbach's alpha of 0.66 (Karakulak Aydemir \& Alparslan 2016).

\section{Center for Epidemiologic Studies' Depression Scale (CES-D)}

The CES-D was planned to measure depressive symptoms and to determine people at risk of having a depressive disorder. The Turkish version of the CES-D, developed by Y1lmaz with Cronbach's alpha of 0.85 (Y1lmaz 2010), was used in the presented study. It consists of 20 items that can be responded to on a fourpoint Likert scale, with response categories ranging from zero points, "rarely or none of the time" to 3 points, "most or all of the times" which are summed to give a total score, where higher score indicates more severe depressive symptoms. A cut-off score of $\geq 16$ is usually used as an indicator for clinical meaningful depressive symptoms.

\section{Beck Anxiety Inventory (BAI)}

Anxiety was assessed using the BAI. The BAI was designed by Beck et al. (1988) to detect the frequency of symptoms of anxiety in adults and adolescents. The Turkish version of the BAI was developed by Ulusoy et al. (1998) and has a Cronbach's alpha of 0.93. The inventory comprises of 21 items descriptive of subjective, somatic, or panic-related symptoms of anxiety. Self-reported answers are based on a 4-point Likert scale ranging from responses of 'not at all' to 'severe' regarding the experience of that symptom over the past month. A high total score shows more severe levels of anxiety.

\section{Statistical analysis}

Data were analyzed using Statistical Package for Social Science for Windows Release 16.0 (SPSS Inc., Chicago, Illinois, USA). Descriptive statistics including mean and frequency distribution were calculated for categorical data. To determine the association between variables, we used the Student t-test, Kruskal-Wallis Analysis of Variance, for quantitative data. Pearson correlation coefficients were also used to examine the associations between the CES-D, BAI, PAI, and MIB scores. The level of significance was taken at $\mathrm{p}$-values less than 0.05 .

\section{RESULTS}

We determined that our study population was in the third decade, mean age of pregnant women was 22.4 years $(\mathrm{SD}=5.7)$, the level of education was low, the ratio of expanded family, unemployment and income equal to expenditure was high.

The findings will be defined in three sections. First, depression, anxiety, prenatal attachment and postpartum mother-baby bonding levels from the sample. Second, factors affecting prenatal attachment and postpartum mother-baby bonding levels from the sample. Third, correlation and regression analyses will be provided as part of an examination of the links between depression, anxiety, and attachment.

\section{Depression, anxiety, prenatal attachment and postpartum mother-baby bonding levels}

According to the finding of this study, the mean PAI scores of the pregnant women was $57.1(\mathrm{SD}=11.5)$ and the mean score of the MIBS was $1.2(\mathrm{SD}=1.5)$. The CES$\mathrm{D}$ score of the study population was $17.57(\mathrm{SD}=10.10)$ $(\min -\max =2-55)$ during pregnancy and $13.54(\mathrm{SD}=9.60)$ $(\min -\max =0-56)$ in postpartum period. Also, the BAI score of the study population was $19.16(\mathrm{SD}=10.08)$ (min-max $=0-47)$ during pregnancy and $11.83(\mathrm{SD}=8.24)$ ( $\min -\max =0-41)$ in the postpartum period (Figure 1). Figure 2 shows the percentage of the mean CES-D scores less than or equal to 15 and greater than or equal to 16 . We found that, with the cut-off of 16, $115(50.7 \%)$ of 227 pregnant women had prenatal depression and 83 (36.6\%) of 227 pregnant women had postpartum depression. 


\section{Factors affecting prenatal attachment} and postpartum mother-baby bonding levels during the pregnancy and postpartum period

Table 1 shows the PAI and MIBS of pregnant women who became pregnant at 35 years-old or older, have lower levels of education, are unemployed, have not got/absent liveborn parity, and have lower prenatal attachment score (respectively $\mathrm{p}=0.002 ; \mathrm{p}=0.0001$; $\mathrm{p}=0.001 ; \mathrm{p}=0.000$ ). We found that have a baby of unwanted gender affected postpartum mother-baby bonding $(\mathrm{p}=0.009)$.

\section{Relationship among the study variables}

We detected a negative relationship between depression and mother-baby bonding level, during pregnancy and the postpartum period $(\mathrm{r}=0.174, \mathrm{p}=0.009$; and $\mathrm{r}=0.221, \mathrm{p}=0.001$, respectively). Although no association was found between anxiety and mother-baby bonding level during pregnancy, a negative relation was found between them in the postpartum period $(\mathrm{r}=0.151$, $\mathrm{p}=0.023$ ). Also, we found that as the prenatal bonding level increase, the level of postpartum bonding is aslo increased $(\mathrm{r}=0.297, \mathrm{p}=0.000)$ (Table 2).

Table 1. PAI and MIBS scores by sociodemographic and obstetric characteristics among women during the pregnancy and postpartum period

\begin{tabular}{|c|c|c|c|}
\hline \multirow{2}{*}{ Characteristics } & \multirow{2}{*}{$\begin{array}{l}\text { Total sample } \\
(\mathrm{N}=227, \%)\end{array}$} & PAI & MIBS \\
\hline & & Pregnancy Mean \pm Std. Dev. & Postpartum Mean \pm Std. Dev. \\
\hline \multicolumn{4}{|l|}{ Age groups (Years) } \\
\hline$<20^{\mathrm{a}}$ & $12(5.3)$ & $64.67 \pm 6.61$ & $1.08 \pm 1.44$ \\
\hline $20-34^{\mathrm{b}}$ & $183(80.6)$ & $57.53 \pm 11.27$ & $1.09 \pm 1.38$ \\
\hline$>34^{\mathrm{c}}$ & $32(14.1)$ & $51.75 \pm 12.04$ & $1.62 \pm 1.80$ \\
\hline $\mathrm{P}^{*}$ value & & 0.002 & 0.037 \\
\hline Significant difference & & $\mathrm{c}<\mathrm{a}, \mathrm{b}$ & \\
\hline \multicolumn{4}{|l|}{ Level of Education } \\
\hline$<$ High School & $131(57.7)$ & $53.94 \pm 11.84$ & $1.29 \pm 1.55$ \\
\hline$\geq$ High School & $96(42.3)$ & $61.40 \pm 9.40$ & $1.00 \pm 1.31$ \\
\hline $\mathrm{P}^{* *}$ value & & 0.0001 & 0.139 \\
\hline \multicolumn{4}{|l|}{ Type of family } \\
\hline Nuclear & $147(64.8)$ & $57.65 \pm 11.08$ & $11.13 \pm 1.53$ \\
\hline Expanded & $80(35.2)$ & $56.06 \pm 12.16$ & $1.22 \pm 1.32$ \\
\hline $\mathrm{P}^{* *}$ value & & 0.317 & 0.662 \\
\hline \multicolumn{4}{|l|}{ Liveborn parity } \\
\hline $\mathrm{No}^{\mathrm{a}}$ & $77(33.9)$ & $63.89 \pm 9.14$ & $0.85 \pm 1.13$ \\
\hline $0-2^{b}$ & $86(37.9)$ & $55.98 \pm 10.67$ & $1.26 \pm 1.62$ \\
\hline$\geq 2^{c}$ & $64(28.2)$ & $50.40 \pm 10.67$ & $1.40 \pm 1.52$ \\
\hline $\mathrm{P}^{* \overline{* * *}}$ value & & 0.000 & 0.60 \\
\hline Significant difference & & $a>b, c$ & \\
\hline \multicolumn{4}{|l|}{ Planned pregnancy } \\
\hline Yes & $125(55.1)$ & $57.51 \pm 11.41$ & $1.12 \pm 1.39$ \\
\hline No & $102(44.9)$ & $56.58 \pm 11.57$ & $1.22 \pm 1.54$ \\
\hline $\mathrm{P}^{* *}$ value & & 0.547 & 0.589 \\
\hline \multicolumn{4}{|l|}{ History of pregnancy loss } \\
\hline Yes & $69(30.4)$ & $55.60 \pm 11.97$ & $1.20 \pm 1.70$ \\
\hline No & $158(69.6)$ & $57.74 \pm 11.22$ & $1.15 \pm 1.34$ \\
\hline $\mathrm{P}^{* *}$ value & & 0.197 & 0.809 \\
\hline \multicolumn{4}{|l|}{ The sex of the baby want } \\
\hline Wanted & $150(66.1)$ & $57.58 \pm 11.46$ & $0.98 \pm 1.34$ \\
\hline Unwanted & $77(33.9)$ & $56.14 \pm 11.50$ & $1.51 \pm 1.61$ \\
\hline $\mathrm{P}^{* *}$ value & & 0.371 & 0.009 \\
\hline \multicolumn{4}{|l|}{ Employment status } \\
\hline Employed & $35(15.4)$ & $62.80 \pm 9.41$ & $1.20 \pm 1.49$ \\
\hline Unemployed & $192(84.6)$ & $56.06 \pm 11.53$ & $1.16 \pm 1.46$ \\
\hline $\mathrm{P}^{*}$ value & & 0.001 & 0.886 \\
\hline \multicolumn{4}{|l|}{ Economic status (self-reported) } \\
\hline Income less than expenditure ${ }^{a}$ & $73(32.2)$ & $54.73 \pm 12.17$ & $1.42 \pm 1.71$ \\
\hline Income equal expenditure & $131(57.7)$ & $57.68 \pm 10.83$ & $1.07 \pm 1.28$ \\
\hline Income more than expenditure & $23(10.1)$ & $61.30 \pm 11.60$ & $0.91 \pm 1.50$ \\
\hline $\mathrm{P}^{* * *}$ value & & 0.050 & 0.203 \\
\hline
\end{tabular}

Legend: ${ }^{*}$ Kruskal-Wallis Analysis of Variance, ${ }^{* *}$ t-Test; ${ }^{* * *}$ One-Way Anova; Chi square significant at $\mathrm{p}<0.005$

PAI $=$ Prenatal Attachment Inventory; MIBS $=$ The Mother-to-Infant Bonding Scale;

CES-D = Center for Epidemiologic Studies' Depression Scale; BAI = Beck Anxiety Inventory 
Table 2. Relationship between depression, anxiety, prenatal attachment and mother-infant bonding level during pregnancy and postpartum period $(\mathrm{N}=227)$.

\begin{tabular}{lcccc} 
& PAI & & MIBS \\
\hline CED-S & R & P & R & P \\
Pregnancy & -0.104 & 0.117 & 0.174 & 0.009 \\
$\quad$ Postpartum & 0.010 & 0.875 & 0.221 & 0.001 \\
BAI & & & & 0.083 \\
Pregnancy & 0.033 & 0.626 & 0.115 & 0.023 \\
$\quad$ Postpartum & 0.084 & 0.208 & 0.151 & 0.000 \\
PAI & & & -0.297 & \\
\hline
\end{tabular}

Legend: Chi square significant at $\mathrm{p}<0.005$; PAI = Prenatal Attachment Inventory; MIBS = The Mother-to-Infant Bonding Scale; $\mathrm{CES}-\mathrm{D}=$ Center for Epidemiologic Studies' Depression Scale; BAI = Beck Anxiety Inventory

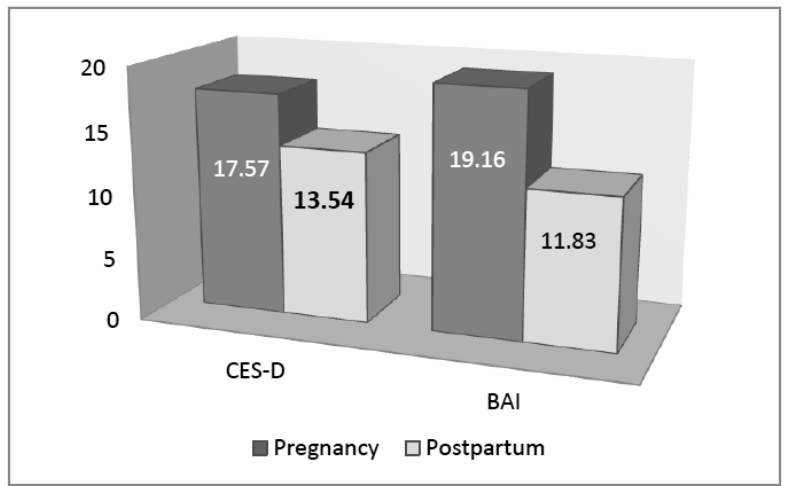

Figure 1. Mean of CES-D and BAI scores during pregnancy and in postpartum period $(\mathrm{N}=227)$

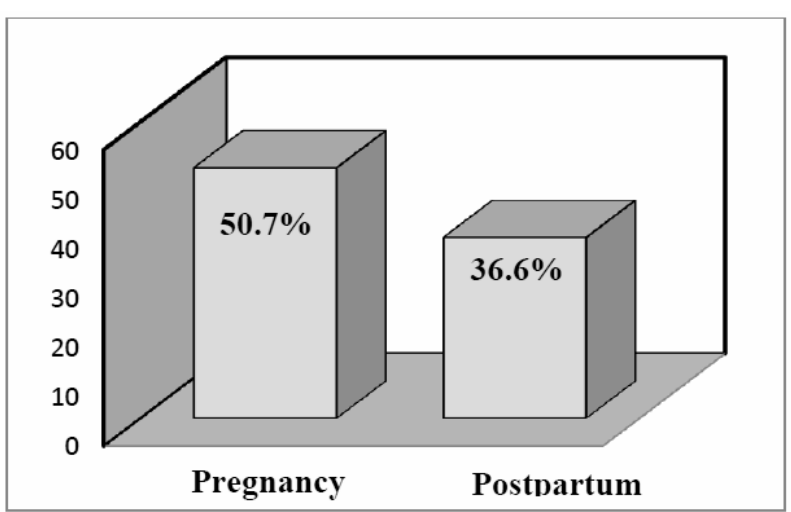

Figure 2. Percentage of CES-D scores during pregnancy and in postpartum period $(\mathrm{N}=227)$

\section{DISCUSSION}

Depression is a common, major health issue that negatively affects many women and their families, and the development of their babies. In studies conducted to determine the level of depression during pregnancy and the postpartum period, there are conflicting results. While the depression risk in pregnant women was determined as $30 \%$ in the last trimester and $9 \%$ in the postpartum period by Setse et al. (2009), these values were $20.8 \%$ and $16.3 \%$ respectively in Glasser et al.'s study (2012). These studies indicate that depressive symptoms are more common during pregnancy than during the postpartum period. Consistent with these findings, CES-D scores in this study were 16 and over in $50.7 \%$ of par- ticipants during pregnancy and in $36.6 \%$ of participants during the postpartum period (Figure 2). In contrast, other studies have indicated that depression levels are higher during the postpartum period than in the prenatal period (Goecke et al. 2012, Mohammad et al. 2011).

The prevalence of depression during pregnancy varies from culture to culture and from society to society. In studies conducted to determine the prevalence of depression during pregnancy, depression prevalence ranged between $18 \%$ and $30 \%$ (Kurki et al. 2000, Nasreen et al. 2011, Seimry et al. 2009). In studies performed in Turkey, the prevalence of depression during pregnancy varies between $12 \%$ and $58 \%$ (Akbaş et al. 2008, Gölbaşı et al. 2010, Yılmaz \& Kızılkaya 2010). In Turkey, the prevalence of depression and depressive symptoms during the postpartum period has been reported to vary between $15 \%$ and $40 \%$ (Ayvaz et al. 2006, Durukan et al. 2011, Nur et al. 2004). The prevalence of depression during pregnancy $(50.7 \%)$ and the postpartum period $(36.6 \%)$ in the present study are in line with the results of those studies cited above.

The anxiety level during the antepartum period may be higher than that in the postpartum period. This increased anxiety could occur because to the course of pregnancy, the pregnant woman's worries about her health and the baby's health, and her fears for the pregnancy (Sertbaş 1998, Üst et al. 2013). The anxiety level in pregnant women during the prenatal period has been found to be higher than that during the postpartum period (Sertbaș 1998, Sevil et al. 2004, Üst et al. 2013). In the present study, the anxiety levels during pregnancy $(\mathrm{M}=19.2, \mathrm{SD}=10.1)$ were found to be higher than those during the postpartum period $(\mathrm{M}=11.8, \mathrm{SD}=8.2)$, which is consistent with the results of other studies (Figure 1).

In the literature, it has been indicated that maternalfetal attachment levels are high in young mothers (Yilmaz \& Kizilkaya 2010), that attachment level decreases as maternal age increases (Damato 2004), and that there is a strong relationship between the woman's age and the quality of attachment (Hart \& McMahon 2006). Similarly, in the present study, the PAI levels of the participants under the age of 20 were higher than were those of the participants over the age of 35 (Table 1 ), indicating that younger pregnant women are better prepared for motherhood. 
In multiple studies, it has been demonstrated that prenatal attachment levels of highly educated and actively working pregnant women are relatively higher than lowly educated and non-working pregnant women (Yilmaz \& Kizılkaya 2010) and that non-working mothers' maternal-fetal attachment is negatively affected (Seimry et al. 2009). Here, we detected higher prenatal attachment levels in highly educated and actively working pregnant women, which is in line with the above cited studies (Table 1).

In the present study, the level of postpartum motherbaby attachment was not affected by age, education, family type, employment status, and the perception of the economic situation (Table 1). However, findings in the literature vary from one study to another. For example, in Akkoca's study (2009), maternal age was reported to affect attachment during the first week postpartum. Results in the literature regarding whether mothers' education levels affect their postpartum attachment levels are conflicting. For instance, while some studies suggest that mothers' education levels do not affect their attachment levels (Akkoca 2009, Örün et al. 2013), some other studies suggest that as the education level increases so does the mother-infant attachment (Dubber et al. 2015). Of the studies conducted on the effects of socio-economic situation on attachment levels, the one by Örün et al. (2013) supports our results that socio-economic situation does not affect attachment levels. Akkoca (2009) found that there was a significant difference between postpartum mother-baby attachment levels of mothers from different income groups. These conflicting results may have stemmed from the differences in the methods of studies, and from the regional and social differences of the participants.

The results of Cranley (1981) and Seimry et al.'s (2009) studies indicating that the increase in the number of births had negative effects on the mother-infant bonding is consistent with the result of the present study. We found that the number of surviving children significantly affected prenatal bonding level and that attachment levels of the mothers having two or more children were lower. Similar to the results of Siddiqui and Högglöf's (2000), and Damato's (2004) studies, in the present study, the relationship between the baby's sex being different from the desired sex and prenatal attachment was not significant, but a significant result was detected when the baby's sex being different from the desired sex and postpartum attachment (Table 1). In the present study, it is noteworthy that while there was no difference between the prenatal attachments levels of mothers whose baby's sex was the desired sex and those of the mothers whose baby's sex was not the desired sex, there was a difference between their postpartum attachment levels. This difference may have stemmed from the fact that the mothers whose baby's sex was the desired sex displayed maternal behaviors, such as willing to see, touch, feed and provide care for the baby during the postpartum period. However, in Akkoca's (2009) study, no relationship was detected between the mothers' postpartum attachment levels and their preferences for male or female children. This suggests that women today still have gender preferences for children or they may face pressures from other members of the family and other people around.

As in this study, several other studies in the literature found that the depression level during pregnancy (Hart \& McMahon 2006, Seimry et al. 2009, Ohoka et al. 2014) and during the postpartum period (Dubber et al. 2015, Karakulak Aydemir \& Alparslan 2016, Kitamura et al. 2013, Kokubu et al. 2012, Ohoka et al. 2014) adversely affect the postpartum mother-infant attachment (Table 2). Goecke et al. (2012) found that women with low scores of depression during pregnancy have a high quality of prenatal attachment, which is consistent with the result of the present study. Ohoka et al. (2014) and Örün et al. (2013) used the MIBS to determine the level of postpartum motherinfant attachment and found a positive relationship between the MIB scores and postpartum depression risk, which is consistent with the result obtained in the present study. Because high scores obtained from the MIBS indicate that the attachment is negative, the more the postpartum depression risk increases, the more adversely the mother-infant attachment is affected.

After Gaffney (1986) had reported that the relationship between the anxiety level and maternal-fetal attachment was not strong, Yarcheski et al. (2009) conducted a meta-analysis study on the determinants of maternalfetal attachment and reached a similar conclusion. While both Gaffney's (1986) and Yarcheski et al.'s (2009) studies support the present study's findings, indicating that anxiety levels during pregnancy do not affect prenatal and postpartum attachment levels (Table 2), Hart and McMahon (2006) found that high anxiety levels negatively affected prenatal attachment. Kokubu et al. (2012) considered this finding indicating the negative relationship between anxiety experienced during pregnancy and mother-infant attachment on the 5th day postpartum as important. Dubber et al. (2015) also found that the anxiety experienced during pregnancy significantly adversely affected the postpartum motherinfant attachment.

The results of this present study indicate that postpartum anxiety negatively affects postpartum attachment (Table 2). In her meta-analysis study on maternalfetal attachment, Cannella (2005) reported that there was a relationship between anxiety and maternal-fetal attachment. In their study (2015), Dubber et al. (2015) found that anxiety experienced during the postpartum period significantly adversely affected postpartum maternal-fetal attachment. Stressful parenting experiences, such as having difficulty breastfeeding after birth or baby's suffering from intestinal colic or baby's persistent crying, cause mothers to bear negative feelings towards the baby and to suffer from anxiety and depression. 
Similar to previous studies (Dubber et al. 2015, Müller 1996, Siddiqui \& Hagglöf 2000, van Bussel et al. 2010), this present study found a positive relationship between prenatal attachment and postpartum attachment $(\mathrm{r}=0.297)$. Because prenatal attachment is an important factor contributing to postpartum attachment, mothers with high levels of prenatal attachment can establish a more sophisticated interaction with infants during the postpartum period (Siddiqui \& Hagglöf, 2000). Mothers having high levels of prenatal attachment with their unborn babies experience less negative mother-infant attachment during the postpartum period (Dubber et al. 2015).

\section{CONCLUSION}

Our findings suggest that depression and anxiety levels are higher during pregnancy than the postpartum period. Depression level during pregnancy and postpartum period depression and anxiety level negatively affect mother-baby bonding in the postpartum period. We found that as the prenatal attachment level increases, the level of postpartum bonding also increases. Thus, prenatal care is a good occasion to assess the attachment of the mother to the unborn child. In prenatal period nurses/midwives are in a unique position to assess attachment and to attempt to promote attachment behaviors.

\section{Acknowledgements:}

This work was supported by the Cumhuriyet University Scientific Research Project [T-560, 2013]. The language of the manuscript has been edited to Proof-Reading-Service.com. The research was presented as a oral statement at Care4 International Scientific Nursing and Midwifery Congress, (4-6 February 2015, Antwerp, Belgium).

\section{Conflict of interest: None to declare.}

\section{Contribution of individual authors:}

Daglar Gulseren: design of the study, literature searches and analyses, application of research, statistical analyses, interpretation of data, first draft and revising it critically for important intellectual content; approval of the final version;

Nur Naim: design of the study, statistical analyses, interpretation of data,first draft and revising it critically for important intellectual content; approval of the final version.

\section{References}

1. Akbaş E, Vurıt O, Kalenderoğlu A, Savaş AH, Sertbaş G: Association between sociodemographic variables with the levels of depression and anxiety in pregnancy. Archives of Neuropsychiatry 2008; 45:85-91

2. Akkoca Y: Factors effecting bonding in the postpartum perlod. PhD. diss. Psychiatry 2009
3. Ayvaz S, Hocaoğlu Ç, Tiryaki A, Ak I: Incidence of postpartum depression in Trabzon province and risk factors at gestation. Turkish Journal of Psychiatry 2006; 17:243-51

4. Beck AT, Steer RA, Carbin MG: Psychometric properties of the Beck Depression Inventory: Twenty-five years of evaluation. Clinical Psychology Review 1988; 8: 77-100

5. Britton JR: Infant temperament and maternal anxiety and depressed mood in the early postpartum period. Womens Health 2011; 51: 55-71

6. Brockington I. Postpartum psychiatric disorders. Lancet 2004; 363: 303-10

7. Cannella BL: Maternal-fetal attachment: an integrative review. Journal of Advanced Nursing 2005; 50: 60-8

8. Cantwell R. \& Cox JL: Psychiatric disorders in pregnancy and the puerperium. Curr Obstet Gynaecol 2003; 13: 7-13

9. Cranley MS: Development of a tool for the measurement of maternal attachment during pregnancy. Nursing Research 1981; 30: 281-84

10. Damato EG: Predictors of prenatal attachment in mothers of twins. JOGNN 2004; 33: 436-45

11. Dennis CL. \& Ross L: Women's perceptions of partner support and conflict in the development of postpartum depressive symptoms. Journal Compilation 2006; 56:588-99

12. Dubber S, Reck C, Müller M, Gawlik S: Postpartum bonding: the role of perinatal depression, anxiety and maternal-fetal bonding during pregnancy. Arch Womens Ment Health 2015; 18: 187-95

13. Durukan E, Ilhan MN, Bumin MA, Aycan S: Postpartum depression frequency and quality of life among a group of mothers having a child aged 2 weeks-18 months. Balkan Med J 2011; 28: 385-93

14. Figueiredo B, \& Costa R: Mother's stress, mood and emotional involvement with the infant: 3 months before and 3 months after childbirth. Arch Womens Ment Health 2009; 12: $143-53$

15. Gaffney KF: Maternal-fetal attachment in relation to selfconcept and anxiety. Maternal Child Nursing Journal 1986; 15:91-101

16. Glasser S, Tanous M, Shihab S, Goldman N, Ziv A, Kaplan G: Perinatal depressive symptoms among Arab women in Northern Israel. Matern Child Health J 2012; 16:1197-205

17. Goecke TW, Voigt F, Faschingbauer F, Spangler G, Beckmann MW, Beetz A: The association of prenatal attachment and perinatal factors with pre-and postpartum depression in first-time mothers. Arch Gynecol Obstet 2012; 286:309-16

18. Golbasi Z, Kelleci M, Kisacik G, Cetin A: Prevalence and correlates of depression in pregnancy among Turkish women. Matern Child Health J 2010; 14:485-91

19. Hart $R \&$ McMahon $C A$ : Mood state and psychological adjustment to pregnancy. Arch Womens Ment Health 2006; 9:329-37

20. Heron J, O'Connor TG, Evans J, Golding J, Glover V: The course of anxiety and depression through pregnancy and the postpartum in a community sample. Journal of Affective Disorders 2004; 80:65-73

21. Karakulak Aydemir H, Alparslan Ö: Adaptation of mother to infant bonding scale to the Turkish Society: Aydin Sample. Journal of Contemporary Medicine 2016; 6:188-99

22. Kitamura T, Ohashi Y, Kita S, Haruna M, Kubo R: Depressive mood, bonding failure, and abusive parenting among mothers with three-month-old babies in a Japanese community. Open Journal of Psychiatry 2013; 3: 1-7 
23. Kokubu M, Okano T, Sugiyama T: Postnatal depression, maternal bonding failure, and negative attitudes towards pregnancy: a longitudinal study of pregnant women in Japan. Arch Womens Ment Health 2012; 15:211-16

24. Kumar RC: 'Anybody's child': Severe disorders of motherto-infant bonding. Br. J. Psychiatry 1997; 171:175-81

25. Kurki T, Hiilesmaa V, Raitasalo R, Mattila H, Ylikorkala O: Depression and anxiety in early pregnancy and risk for preeclampsia. Obstetrics and Gynecology 2000; 95: 487-90

26. Mercer RT: Becoming a mother versus maternal role attainment. J Nurs Scholarsh 2004; 36: 226-32

27. Mohammad KI, Gamble J, Creedy DK: Prevalence and factors associated with the development of antenatal and postnatal depression among Jordanian women. Midwifery 2011; 27: e238-e245

28. Muller ME: Development of the Prenatal Attachment Inventory. Western J Nurs Res 1993; 15: 199-211

29. Muller ME: Prenatal and postnatal attachment: A modest correlation. J Obstet Gynecol Neonatal Nurs 1996; 25:161-66

30. Murray L, Fiori-Cowley A, Hooper R, Cooper PJ: The impact of postnatal depression and associated adversity on early mother infant interactions and later infant outcome. Child Dev 1996a; 67: 2512-26

31. Murray L, Hipwell A, Hooper R, Stein A, Cooper P: The cognitive development of 5-year-old children of postnatally depressed mothers. Child Psychol Psychiatry 1996b; 37: 927-35

32. Nasreen H, Kabir ZN, Forsell Y, Edhborg M: Prevalence and associated factors of depressive and anxiety symptoms during pregnancy: A population based study in rural Bangladesh. BMC Womens Health 2011; 11: 22

33. Nur N, Çetinkaya S, Bakır DA, Demirel Y: Prevalence of postnatal depression and risk factors in women in Sivas city. C.U. Medical Faculty Magazine 2004; 26: 55-9

34. Ohoka H, Koide T, Goto S, Murase S, Kanai A, Masuda et al: Effects of maternal depressive symptomatology during pregnancy and the postpartum period on infant-mother attachment. Psychiatry Clin Neurosci 2014; 68: 631-9

35. O'Keane $V$ \& Marsh MS: Depression during pregnancy. BMJ 2007; 334: 1003-5

36. Örün E, Yalçın SS, Mutlu B: Relations of maternal psychopathologies, social-obstetrical factors and motherinfant bonding at 2-month postpartum: a sample of Turkish mothers. World J Pediatr 2013; 9: 350-55

37. Ranson E, Urichuk LJ: The effect of parent - child relationships on child biopsychosocial outcomes: a review. Early Child Dev Care 2008; 2: 129-52

38. Ross LE \& McLean LM: Anxiety disorders during pregnancy and the postpartum period: a systematic review. J Clin Psychiatry 2006; 67:1285-98
39. Seimyr L, Sjögren B, Welles-Nyström B, Nissen E: Antenatal maternal depressive mood and parental-fetal attachment at the end of pregnancy. Arch Womens Ment Health 2009; 12: 269-79

40. Sertbas G: Investigation of anxiety level at pregnant in the state trait prenatal and postpartum period. PhD. diss. 1998

41. Setse R, Grogan R, Pham L, Cooper LA, Strobino D, Powe $N R$. et al: Longitudinal study of depressive symptoms and health-related quality of life during pregnancy and after delivery: The Health Status in Pregnancy (HIP) study. Matern Child Health J 2009; 13: 577-87

42. Sevil DÜ, Saruhan A, Ertem G, Kavlak O: The determination of pre and post-labor stage anxiety and depression levels of women and to assess the factors that effect the anxiety and depression levels. Dokuz Eylul University Faculty of Medical Journal 2004; 18:67-76

43. Siddiqui $A$ \& Högglöf B: Does maternal prenatal attachment predict postnatal mother-infant interaction? Early Human Development 2000; 59: 13-25

44. Stocky $A$ \& Lynch J: Acute psychiatric disturbance in pregnancy and the puerperium. Bailliere's Clinical Obstetrics and Gynaecology 2000; 14: 73-87

45. Taylor A, Atkins R, Kumar R, Adams D, Glover VA: New mother to infant bonding scale: links with early maternal mood. Arch Womens Ment Health 2005; 8: 45-51

46. Ulusoy M, Sahin NH, Erkmen H: Turkish version of the Beck Anxiety Inventory: Psychometric properties. J Cogn Psychother 1998; 12: 163-72

47. Üst ZD, Pasinlioğlu T, Özkan H: Investigation of anxiety levels of pregnant women in labor. Anadolu Nursing and Health Sciences Journal 2013;16: 110-15

48. van Bussel JCH, Spitz B, Demyttenaere K: Three self-report questionnaires of the early mother-to-infant bond: reliability and validity of the Dutch version of the MPAS, $P B Q$ and MIBS. Arch Womens Ment Health 2010; 13: 373-84

49. Yarcheski A, Mahon NE, Yarcheski TJ, Hanks MM, Cannella BL: A meta-analytic study of predictors of maternal-fetal attachment. International Journal of Nursing Studies 2009; 46: 708-15

50. Yllmaz DS: The effect of perinatal loss experience to subsequent pregnancy. PhD. diss., Obstetrics and Gynecology Nursing 2010

51. Yllmaz DS \& Klzllkaya BN: Levels of coping with stres, depression and prenatal attachment and affecting factors of pregnant women. General Medical Journal 2010; 20 : 99-08

52. Yllmaz DS \& Klzllkaya BN: Turkish version of prenatal attachment inventory: a study of reliability and validity. Anatolian Journal of Nursing and Health Sciences 2013; 16: 103-09

Correspondence:

Assistant Professor Gulseren Daglar, PhD, RN

Cumhuriyet University Faculty of Health Sciences, Department of Midwifery

58140, Sivas, Turkey

E-mail: gulserendaglar@gmail.com 